\title{
Methicillin resistant Staphylococcus aureus (MRSA) infection in cystic fibrosis
}

\author{
L S Miall, N T McGinley, K G Brownlee, S P Conway
}

\begin{abstract}
Background-Methicillin resistant Staphylococcus aureus (MRSA) infection is increasingly found in patients with cystic fibrosis (CF).

Aims-To determine whether MRSA infection has a deleterious effect on the clinical status of children with CF.

Methods-Children with MRSA in respiratory cultures during a seven year period were identified and compared with controls matched for age, sex, and respiratory function. Respiratory function tests, anthropometric data, ShwachmanKulczycki score, Northern chest $x$ ray score, intravenous and nebulised antibiotic therapy, and steroid therapy were compared one year before and one year after MRSA infection.
\end{abstract}

Results-From a clinic population of 300 , 10 children had positive sputum or cough swab cultures for MRSA. Prevalence rose from 0 in 1992-1994 to 7 in 1998. Eighteen controls were identified. Children with MRSA showed significant worsening of height standard deviation scores and required twice as many courses of intravenous antibiotics as controls after one year. They had significantly worse chest $x$ ray scores at the time of the first MRSA isolate and one year later, but showed no increase in the rate of decline in chest $x$ ray appearance. There was a trend towards lower $\mathrm{FEV}_{1}$ and $\mathrm{FEF}_{25-75}$ in children with MRSA. There were no significant differences between the two groups with respect to change in weight, body mass index, or Shwachman score. There was no significant difference in prior use of steroids or nebulised antibiotics.

Conclusion-MRSA infection in children with CF does not significantly affect respiratory function, but may have an adverse effect on growth. Children with MRSA require significantly more courses of intravenous antibiotics and have a worse chest $\boldsymbol{x}$ ray appearance than controls. (Arch Dis Child 2001;84:160-162)

Keywords: cystic fibrosis; MRSA; methicillin resistant Staphylococcus aureus

Chronic lung infection in cystic fibrosis $(\mathrm{CF})$ is associated with Pseudomonas aeruginosa, Haemophilus influenzae, and Staphylococcus aureus infection. $S$ aureus is most commonly seen in younger patients. ${ }^{1}$ Methicillin resistant $S$ aureus (MRSA) was first identified in $1960 .^{2}$ It has been an occasional isolate in sputum from patients with $\mathrm{CF}$ over the last three decades, but there is evidence of increasing prevalence, ${ }^{34}$ with $10 \%$ of patients infected in one epidemiological study. ${ }^{5}$ There has been a general increase in MRSA infection in paediatric patients. ${ }^{67}$ The increased prevalence seen in CF may also reflect the widespread use of flucloxacillin for $S$ aureus infection. Some units prescribe lifelong flucloxacillin prophylaxis from the time of diagnosis.

The clinical significance of MRSA infection in CF is not known. Although it has been thought not to effect morbidity or mortality, ${ }^{3} 8$ no studies have systematically examined the effect of MRSA infection on respiratory function or nutritional status and none has documented its effects in children with CF.

MRSA may be associated with stigmatisation and social isolation, ${ }^{48}$ with resulting adverse psychological effects. ${ }^{9}$ Most CF centres recommend isolating patients with MRSA from the rest of the clinic population, ${ }^{48}$ although one centre suggested infection was more commonly acquired from other hospital patients than from other CF patients. ${ }^{10}$ MRSA infection is a relative contraindication to lung transplantation in some centres. ${ }^{4}$ There is still no consensus on the best method of treatment and on whether eradication is effective. ${ }^{8}$

The aim of this retrospective case control study was to identify children with MRSA infection from our clinic population and to quantify any impact of the infection on their clinical status.

\section{Methods}

Patients in whom MRSA had been cultured from respiratory secretions in the past seven years were identified and their clinical results examined retrospectively. Each patient was matched where possible with two controls for sex, age ( \pm 1 year), and respiratory function $( \pm 20 \%)$ at the time of the first MRSA isolate. Details of respiratory function, nutritional status, treatment received (including nebulised antibiotics, number of intravenous antibiotic courses, and nebulised, oral, or inhaled steroids), Shwachman-Kulczycki (S-K) score, ${ }^{11}$ and Northern chest $x$ ray score ${ }^{12}$ were documented at the time of MRSA infection, one year before, and one year afterwards. The S-K score measures four parameters: general activity, physical examination, nutrition, and $x$ ray appearance. A maximum score (100) represents normal health. The Northern chest $x$ ray score is a measure of abnormal shadowing on the chest radiograph. A maximum score (20) represents severe radiological abnormality. Nutritional status was calculated as body mass 
Table 1 Characteristics of study patients

\begin{tabular}{lccllll}
\hline $\begin{array}{l}\text { Patient } \\
\text { no. }\end{array}$ & Sex & $\begin{array}{c}\text { Age } \\
(y)\end{array}$ & Genotype & $\begin{array}{l}\text { No of } \\
\text { MRSA } \\
\text { isolates }\end{array}$ & Treatment given & $\begin{array}{l}\text { Colonised } \\
>3 \text { months }\end{array}$ \\
\hline 1 & $\mathrm{~F}$ & 6 & $\Delta \mathrm{F} 508 / \mathrm{N} 1303 \mathrm{~K}$ & 30 & Teicoplanin (iv) & Yes \\
2 & $\mathrm{~F}$ & 11 & $\Delta \mathrm{F} 508 / \Delta \mathrm{F} 508$ & 11 & Clindamycin & Yes \\
3 & $\mathrm{~F}$ & 2.5 & $\Delta \mathrm{F} 508 / \Delta \mathrm{F} 508$ & 2 & Vancomycin (neb) & No \\
4 & $\mathrm{~F}$ & 11 & $\Delta \mathrm{F} 508 / \Delta \mathrm{F} 508$ & 3 & None & Yes \\
5 & $\mathrm{~F}$ & 12 & $\Delta \mathrm{F} 508 / \Delta \mathrm{F} 508$ & 6 & Vancomycin (neb) & Yes \\
6 & $\mathrm{M}$ & 15 & $\mathrm{G} 542 \mathrm{X} / 1154$ insTC & 1 & Fucidic acid & No \\
7 & $\mathrm{M}$ & 7 & $\Delta \mathrm{F} 508 / ?$ & 2 & Clindamycin & No \\
8 & $\mathrm{M}$ & 10 & $\Delta \mathrm{F} 508 / ?$ & 7 & Vancomycin (iv) & Yes \\
9 & $\mathrm{M}$ & 6 & $\Delta \mathrm{F} 508 / \Delta \mathrm{F} 508$ & 2 & Vancomycin (neb) & No \\
10 & $\mathrm{M}$ & 11 & $\Delta \mathrm{F} 508 / \Delta \mathrm{F} 508$ & 1 & Vancomycin (iv) & No \\
\hline
\end{tabular}

Table 2 Characteristics of patients and controls one year before MRSA infection

\begin{tabular}{llllll}
\hline Variable & $\begin{array}{l}\text { Patients } \\
(n=10)\end{array}$ & $95 \% C I$ & $\begin{array}{l}\text { Controls } \\
(n=18)\end{array}$ & $95 \% C I$ & Difference \\
\hline Age & $8.6 \mathrm{y}$ & $6.3,10.9$ & $8.1 \mathrm{y}$ & $6.5,9.7$ & $\mathrm{p}=0.72$ \\
Sex $(\mathrm{M}: \mathrm{F})$ & $5: 5$ & & $8: 10$ & & \\
Height $(\mathrm{cm})$ & 127 & 111,142 & 121 & 110,132 & $\mathrm{p}=0.58$ \\
Weight $(\mathrm{kg})$ & 27.7 & $20.6,34.8$ & 24.5 & $19.3,29.6$ & $\mathrm{p}=0.46$ \\
FEV $_{1}(\%$ predicted $)$ & 68.9 & $54.9,82.9$ & 72.3 & $67.9,77.7$ & $\mathrm{p}=0.67$ \\
FVC $_{\mathrm{FEF}_{25-75}}$ & 86.9 & $74.7,99.0$ & 88.9 & $81.7,96.1$ & $\mathrm{p}=0.79$ \\
Shwachman score & 45.6 & $23.8,67.5$ & 49.7 & $40.9,58.5$ & $\mathrm{p}=0.74$ \\
Northern $x$ ray score & 6.9 & $80.3,88.6$ & 84.7 & $81.9,87.6$ & $\mathrm{p}=0.92$ \\
\hline
\end{tabular}

index (BMI), and height and weight standard deviation scores (z scores), compared with British 1990 standard reference data. ${ }^{13}{ }^{14}$ Respiratory function was measured as forced vital capacity (FVC), forced expiratory volume in one second $\left(\mathrm{FEV}_{1}\right)$, and forced expiratory flow $\left(\mathrm{FEF}_{25-75}\right)$, using the best of three measurements on a Vitalograph Compact II Spirometer (Vitalograph Ltd, Buckingham, UK). Percentage predicted volumes were calculated using $\mathrm{ECCS}^{15}$ and POLGAR ${ }^{16}$ reference values. Statistical comparison was made using unpaired $t$ tests for the continuous variables and Mann-Whitney $U$ tests for the Northern and $\mathrm{S}-\mathrm{K}$ scores. Nebulised antibiotic and steroid use was analysed with the $\chi^{2}$ test.

\section{Results}

MRSA was isolated in sputum or cough swabs from 10 children between 1992 and 1998 from a clinic population of 300 (table 1). Eighteen controls were identified (table 2). In two cases only one control could be found. Case 3 was too young to undergo spirometry.

MRSA was present in five children for more than three months. Seven children cleared their MRSA during the study period, but in three it persisted. The prevalence of MRSA increased from zero to seven children over the period 1992-1998 (see fig 1). Methicillin sensitive strains of $S$ aureus were isolated in four of the

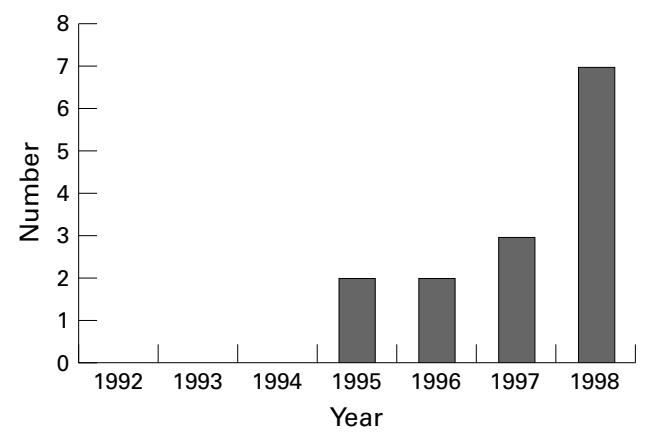

Figure 1 Prevalence of MRSA 1992-1998.

controls and none of the patients during the study. An equal proportion of both groups were infected with $P$ aeruginosa, $H$ influenzae, and Aspergillus fumigatans. One of the MRSA group has Burkholderia cepacia.

Changes in respiratory function, nutritional status, $\mathrm{S}-\mathrm{K}$ score, and Northern $x$ ray score from one year before to one year after the patients acquired MRSA were calculated (see table 3). The MRSA group showed a deterioration in weight, height, and body mass index $\mathrm{z}$ scores. These variables improved in the control group. The difference was significant for height $(p<0.05)$.

There was a trend towards greater deterioration in $\mathrm{FEV}_{1}$ and $\mathrm{FEF}_{25-75}$ in the MRSA group. There was a slight worsening of the median $\mathrm{S}-\mathrm{K}$ score in the MRSA group compared with controls, but this was not significant. Northern $x$ ray scores were significantly worse in the MRSA group than controls at the time of MRSA infection (10 v 5.5, $\mathrm{p}=0.013)$ and one year later $(11.5 \vee 7.5, \mathrm{p}=0.014)$. The overall change in $x$ ray score over the two years was not significantly different between patients and controls.

There was no significant difference in the number of intravenous antibiotic courses received in the year prior to MRSA infection (1.6 $v 1.1$ ), but children with MRSA had significantly more courses of intravenous therapy in the year after MRSA infection (2.7 $v$ $1.2, \mathrm{p}=0.046)$.

The MRSA group were more likely to have been treated with corticosteroids $(80 \% v 61 \%)$ and nebulised antibiotics ( $60 \%$ v 55\%) than controls but these differences were not significant.

\section{Discussion}

Staphylococcus aureus may be isolated from the sputum of approximately half the patients with

Table 3 Changes in variables from one year before to one year after MRSA infection

\begin{tabular}{|c|c|c|c|c|c|}
\hline & \multicolumn{2}{|c|}{ MRSA patients $(n=10)$} & \multicolumn{2}{|c|}{ Controls $(n=18)$} & \multirow[b]{2}{*}{ Student's $t$ test } \\
\hline & Mean & $95 \% C I$ & Mean & $95 \% C I$ & \\
\hline Change in weight (SDS) & -0.22 & $-0.42,-0.02$ & +0.133 & $-0.17,0.45$ & $\mathrm{p}=0.067$ \\
\hline Change in height (SDS) & -0.27 & $-0.54,0.00$ & +0.08 & $-0.05,0.22$ & $\mathrm{p}=0.039^{\star}$ \\
\hline Change in BMI (SDS) & -0.18 & $-0.46,0.10$ & +0.07 & $-0.35,0.49$ & $\mathrm{p}=0.377$ \\
\hline Change in $\mathrm{FEV}_{1}$ (\% predicted) & -6.31 & $-14.99,2.38$ & -4.44 & $-12.1,3.23$ & $\mathrm{p}=0.788$ \\
\hline Change in FVC (\% predicted) & -0.67 & $-11.73,10.39$ & -1.26 & $-10.08,7.56$ & $\mathrm{p}=0.927$ \\
\hline Change in $\mathrm{FEF}_{25-75}$ (\% predicted) & -8.83 & $-18.99,1.32$ & -2.96 & $-16.39,10.48$ & $\mathrm{p}=0.611$ \\
\hline & Median & & Median & & Mann-Whitney $U$ test \\
\hline Change in Shwachmann score & -2.5 & $-9.7,4.7$ & 0 & $-4.5,4.5$ & $\mathrm{p}=0.33$ \\
\hline Change in Northern $x$ ray score & +2 & $-0.1,4.1$ & +1 & $-0.5,2.5$ & $\mathrm{p}=0.16$ \\
\hline
\end{tabular}


CF. ${ }^{3}$ MRSA occurs less frequently but its prevalence is increasing ${ }^{48}$ with rates ranging from $2.6 \%$ to $9.8 \% .^{3-5} 10$ Our study showed a prevalence of MRSA in children with CF of $3 \%$.

Few studies have examined the clinical significance of MRSA in upper and lower respiratory tract secretions in CF patients and none in children. In one study of 14 patients in which MRSA was untreated, eight reported an increase in respiratory symptoms. ${ }^{3}$ Ten patients eventually lost their MRSA and one patient died although MRSA was not implicated. A study of $26 \mathrm{CF}$ patients aged 11.8 to 43.3 years showed $96 \%$ had colonisation of the lower airway, though in $35 \%$ this lasted less than one month. Mean $\mathrm{FEV}_{1}$ was $28.9 \%$. The authors conclude that there are no important clinical consequences from MRSA infection other than those associated with isolating patients. ${ }^{4}$

Our study attempted to quantify the effect of MRSA on the clinical status of children with $\mathrm{CF}$ by looking at nutritional status, respiratory function, and chest $x$ ray appearance. Height, weight, and body mass index deteriorated in the MRSA group compared with reference data over the two year study period. These parameters improved in the control group over the same period. The differences were significant for height. MRSA infection may have an adverse effect on nutritional status and growth.

The MRSA group showed a trend towards a greater reduction in $\mathrm{FEV}_{1}, \mathrm{FEF}_{25-75}$, and $\mathrm{S}-\mathrm{K}$ score than controls. MRSA infection does not appear to have a significant adverse effect on respiratory function or clinical status.

Most patients received therapy to try to eradicate the MRSA. The MRSA group required more than twice the number of courses of intravenous antibiotic therapy in the subsequent year compared with controls. The differences remain significant even after discounting therapy aimed at eradication of MRSA. We did not show any significant association between prior use of nebulised antibiotics or inhaled or systemic corticosteroid therapy and MRSA infection.

The patients with MRSA had significantly worse chest $x$ ray appearances than controls, both at the time of MRSA infection and one year after. The change over the two year study period was not significantly different, with both groups showing a slight deterioration in $x$ ray appearance. Children with worse lung pathology (as measured by the Northern chest $x$ ray score) may be more predisposed to MRSA infection.

This study has shown that MRSA is increasing in frequency in our paediatric CF population and suggests a significant effect of MRSA on growth. Children with worse pulmonary disease may be more susceptible to MRSA. Nearly all the parameters we measured were worse in the MRSA group. In a larger study these changes may reach significance. A variety of treatments are currently being used to try to eradicate MRSA. A multicentre study is needed to define the effect of MRSA infection on clinical status in $\mathrm{CF}$ and to determine whether treatment of MRSA infection is necessary. Randomised controlled trials will then be necessary to establish what is the most effective treatment for MRSA in CF.

1 Maiz L, Canton R, Mir N, Baquero F, Escobar $\mathrm{H}$. Aerosolized vancomycin for the treatment of methicillin resistant Staphylococcus aureus infection in cystic fibrosis. Pediatr Pulmonol 1998;26:287-9.

2 Jevons MP. "Celbenin" resistant staphylococci. BMf 1961;1:124-5.

3 Boxerbaum B, Jacobs MR, Cechner RL. Prevalence and significance of methicillin-resistant Staphylococcus aureus in patien

4 Thomas SR, Gyi KM, Gaya H, Hodson ME. Methicillinresistant Staphylococcus aureus: impact at a national cystic resistant Staphylococcus aureus: impact at a

5 Branger C, Fournier JM, Loulergue J, et al. Epidemiology of Branger C, Fournier JM, Loulergue J, et al. Epidemiology of
Staphylococcus aureus in patients with cystic fibrosis. Epidemiol Infect 1994;112:489-500.

6 Storch GA, Rajagopalan L. Methicillin-resistant Staphylococcus aureus bacteraemia in children. Pediatr Infect Dis 1986;5:59-67.

7 McAllester TA, Mocan H, Murphy AV, Beattie TJ. tonitis in children. F Antimicrob Chemother 1987;19:95100.

8 Rao G, Gaya H, Hodson, et al. MRSA in cystic fibrosis. $\mathcal{F}$ Hosp Infect 1998;40:179-91.

9 MacKenzie D, Edwards A. MRSA: the psychological effects. Nursing Standard 1997;12(11):49-56.

10 Givney R, Vickery A, Holliday A, Pegler M, Benn R. Methicillin-resistant Staphylococcus aureus in a cystic Methicillin-resistant Staphylococcus aur

11 Shwachman H, Kulczycki LL. Long-term study of one hundred and five patients with cystic fibrosis. Am $\mathcal{F}$ Dis Child 1958;96:6-15

12 Conway SP, Pond MN, Bowler I, et al. The chest radiograph in cystic fibrosis: a new scoring system compared with the Chrispin-Norman and Brasfield scores. Thorax 1994;49: $860-2$.

13 Freeman JV, Cole TJ, Chinn S, Jones PRM, White EM, Preece MA. Cross sectional statures and weight reference curves for the UK. Arch Dis Child 1990;73:17-24.

14 Cole TJ, Freeman JV, Preece MA. Body mass index reference curves for the UK. Arch Dis Child 1990;73:25-9.

15 Report of working party. Standardisation of lung function tests. Official statement of the European Community for tests. Official statement of the European Community for
Coal and Steel (ECCS), Luxembourg. Bulletin Europeen de Coal and Steel (ECCS), Luxembourg. Bulletin
Physiopathologie Respiratoire 1983;19(suppl 5).

16 Polgar G, Weng TR. The functional development of the respiratory system - from the period of gestation to adulthood. Am Rev Respir Dis 1979;120:3.

17 Polgar G, Promadhat U. Pulmonary function testing in children; techniques and standards. Philadelphia: WB Saunders and Co., 1971. 